\title{
Composition Effect of Iron-Copper Composite Catalysts in the Fenton Heterogeneous Process Efficiency and Cooxidation Synergy Assessment
}

\author{
André F. Rossi, Rui C. Martins, and Rosa M. Quinta-Ferreira* \\ CIEPQPF-Chemical Process Engineering and Forest Products Research Centre, GERST-Group on Environment, Reaction, \\ Separation and Thermodynamics. Department of Chemical Engineering, Faculty of Sciences and Technology, University of Coimbra, \\ Pólo II-Rua Sílvio Lima, 3030-790 Coimbra, Portugal
}

\begin{abstract}
New iron-copper based solids prepared by coprecipitation had their efficiency in the heterogeneous Fenton process investigated regarding organic charge removal and biodegradability enhancement. Different molar proportions between the two metals were used to assess the best one. Chemical oxygen demand (COD), total phenolic content (TPh), and biochemical oxygen demand in 5 days $\left(\mathrm{BOD}_{5}\right)$ were the parameters used for the evaluation. Two solutions simulated olive mill wastewaters: one comprising six phenolic acids and another containing one extra acid. The efficiency of each catalyst was compared when facing both mixtures, and the one containing more phenolic acids was further decomposed, maybe due to a cooxidation synergistic effect related with the presence of more radicals. All solids proved to be fit for the reaction, and the Fe$\mathrm{Cu}-\mathrm{O} 50 / 50$ catalyst showed the best overall results regarding organic charge removals.
\end{abstract}

\section{INTRODUCTION}

Fenton's process was discovered by H. J. H. Fenton in the end of the 19th century with the oxidation of tartaric acid into dihydroxymaleic acid by hydrogen peroxide in the presence of ferrous ions. ${ }^{1}$ This reaction starts by the dissociation of the oxidant agent $\left(\mathrm{H}_{2} \mathrm{O}_{2}\right)$ and the formation of highly reactive hydroxyl radicals $\left({ }^{\circ} \mathrm{OH}\right)$. With elevated oxidation potential, $2.80 \mathrm{~V},{ }^{2}$ these radicals are able to attack compounds nonspecifically, degrading them in a chain radical reactionwhich makes the tracing of the full degradation pathway very hard to specify in a step by step form. Nevertheless, the basic startup of the whole process was explained more than 80 years ago: production of hydroxyl radicals followed by autocatalysis. ${ }^{3}$

Nowadays, this reaction is an important process used for wastewater treatment, since it is able to oxidize both organic and inorganic compounds at mild conditions of temperature and pressure. The advantages of the Fenton process, besides the low energy requirement and cheap reactants, start with good organics abatement. Biodegradability enhancement is another benefit, since some wastewaters present toxic compounds and, therefore, are not able to be sent to biological treatment plants. This chemical reaction can degrade those substances, diminishing the effluent's toxicity. The same happens with seasonal wastes, which do not exist all over the year, discarding the chance of biological processes.

The homogeneous Fenton presents all of these qualities, but also some negative points: high iron concentrations are required, and this metal needs to be separated by precipitation, usually forced by $\mathrm{pH}$ elevation, which creates final sludgeanother unwanted waste. Studies have been made to avoid those deficiencies, through the so-called Fenton-like processes. These comprise the use of metals different from iron and the heterogeneous Fenton's process as well, in which the iron (or even other metal) is supported in a solid that will not dissolve into the bulk, so it can be separated by simple filtration at the end of the reaction-not requiring a $\mathrm{pH}$ increase and, thus, preventing the formation of sludge and reducing costs.

Previous studies from our investigation group analyzed the efficiency of several catalysts prepared by coprecipitation-as in Imamura et al. ${ }^{4}$ Interactions between cobalt, manganese, and cerium with iron oxides were investigated, and a catalyst composed of iron and cerium at the molar proportion of 70/30 ( $\mathrm{Fe}-\mathrm{Ce}-\mathrm{O} 70 / 30)$ was highlighted. ${ }^{5}$ Further studies included determination of the most indicated calcination temperature for this solid, bringing out the catalyst baked at $300{ }^{\circ} \mathrm{C}$ for $2 \mathrm{~h}^{6}$ The present work introduces a new catalyst also prepared by coprecipitation of iron and copper nitrates at five different iron/ copper molar proportions: 0/100, 30/70, 50/50, 70/30 and $100 / 0$. These solids were tested as catalysts for the Fenton-like process and their efficiency on the depuration of olive mill simulated wastewaters was compared-a very common effluent in Portugal.

All catalysts were evaluated on the oxidative reaction of two different simulated effluents. The first contains $0.1 \mathrm{mg} \cdot \mathrm{L}^{-1}$ of six phenolic acids, and the other has one extra acid (gallic acid) at the same concentration. Since the Fenton process is a radical reaction, the intention of this study is to compare if the presence of acids (and the products of their oxidation) would interfere in the oxidative power of the procedure. In a previous study, this comparison was made by Lopes et al., ${ }^{7}$ using the catalytic wet oxidation method. Altered oxidation behavior was observed when the pollutants were treated isolatedly from the others compared to mixed solutions. It was stated that the

Special Issue: Alírio Rodrigues Festschrift

Received: March 20, 2014

Revised: $\quad$ May 26, 2014

Accepted: May 27, 2014

Published: May 27, 2014 
formation of free-radical intermediates might enhance the compounds degradation-the alleged cooxidation process.

\section{EXPERIMENTAL SECTION}

2.1. Catalyst Preparation and Characterization. This work evaluated five different catalysts composed by different molar proportions between iron and copper (0/100, 30/70, $50 / 50,70 / 30$, and $100 / 0)$. The preparation procedure was obtained from Imamura et al. ${ }^{4}$ First, $100 \mathrm{~mL}$ of a solution containing $15 \mathrm{~g}$ as the sum of both iron (Panreac 98\%) and copper nitrates (and Riedel-de-Haën 99\%) at the desired molar proportion was prepared. Coprecipitation was then induced by the addition of $200 \mathrm{~mL}$ of $3 \mathrm{M} \mathrm{NaOH}$-solution prepared using $\mathrm{NaOH}$ pellets (Panreac 98\%). The resulting mixture was washed several times with an ultrapure water system Milli- $\mathrm{Q}^{50}$ (Millipore) and left to precipitate, and its supernatant was filtered. When $2.5 \mathrm{~L}$ of washing water had been used, the final filtration was done to retain the metals at the paper filter (Double Rings qualitative filter papers-102). The washing had the purpose to remove nitrates and the excess $\mathrm{NaOH}$. The filter was left in an oven at $105{ }^{\circ} \mathrm{C}$ overnight, and then the remaining solids were collected, smashed until the formation of a powder, and calcinated at $300{ }^{\circ} \mathrm{C}$ for $2 \mathrm{~h}$. The temperature/time was chosen due to recent studies with a similar catalyst. ${ }^{6}$ For discussion, the catalysts will be named $\mathrm{Fe}-\mathrm{O}, \mathrm{Fe}-\mathrm{Cu}-\mathrm{O} 70$ / 30, $\mathrm{Fe}-\mathrm{Cu}-\mathrm{O} 50 / 50, \mathrm{Fe}-\mathrm{Cu}-\mathrm{O} 30 / 70$ and $\mathrm{Cu}-\mathrm{O}$.

Catalyst characterization included the following analysis: Brunauer-Emmet-Teller (BET) surface area $\left(S_{\mathrm{BET}}\right)$ determined by nitrogen adsorption at $-196{ }^{\circ} \mathrm{C}$ in a Micrometrics ASAP 2000, X-ray diffraction (XRD) in an X-ray diffractometer Philips model X-Pert with $\mathrm{Co} \mathrm{K} \alpha$ radiation under operation conditions of $40 \mathrm{kV}$ and $35 \mathrm{~mA}$. Data were collected from $2 \theta=$ $20-120^{\circ}$ in $0.025^{\circ}$ steps, from mercury porosimetry and pore size distribution measurement with a Micrometrics poresizer 9320 (penetrometer constant, $10.683 \mu \mathrm{L} \cdot \mathrm{pF}^{-1}$; penetrometer weight, $70.84 \mathrm{~g}$; penetrometer volume, $5.3905 \mathrm{~mL}$; stem volume, $0.392 \mathrm{~mL}$; maximum head pressure, 4.45 psia; room temperature), and from gas picnometry with a Micrometrics AccuPyc 1330 instrument (cell volume, $12.2169 \mathrm{~cm}^{3}$; equilibration rate, $0.0500 \mathrm{psig} \cdot \mathrm{min}^{-1}$; expansion volume, $8.2518 \mathrm{~cm}^{3}$; room temperature). The random errors associated with Micrometrics ASAP 2000 analysis (BET surface area, average pore diameter, and single point total pore volume) are in the range of $\pm 0.1 \%$; for the Micrometrics poresizer (porosity), $\pm 1.0 \%$; and for the Micrometrics AccuPyc 1330 (average density), $\pm 0.03 \%$.

2.2. Synthetic Effluent. One of our research group's major focuses are olive mill wastewaters (OMW). To simulate this kind of effluent, a solution containing $0.1 \mathrm{~g} \cdot \mathrm{L}^{-1}$ of six phenolic acids commonly found in OMW was prepared. They are protocatechuic acid (Acrós Organics, 97\%), 4-hydroxybenzoic acid (Sigma-Aldrich, 99\%), vanillic acid (Sigma-Aldrich, 97\%), 3,4,5-trimethoxybenzoic acid (Sigma-Aldrich 99\%), veratric acid (Sigma-Aldrich, 99\%), and syringic acid (Fluka, 97\%). Another intention of this work was to evaluate the synergy created by the addition of one extra acid to the synthetic solution, the gallic acid (Fluka, 98\%). This addition would increase the radicals present in the bulk after the beginning of the oxidation, since the Fenton process is based on a chain reaction. To ensure the dissolution of those compounds, the mixtures are submitted to ultrasound (Crest ultrasound equipment) during $15 \mathrm{~min}$. Finally, the $\mathrm{pH}$ is adjusted to 3.0 since this is one of the well-known parameters required in order to optimize the procedure. Characteristics of these synthetic effluents are presented in Table 1, where the elevated organic charge and fairly low biodegradability for both solutions can be seen.

Table 1. Synthetic Solutions Characterization

\begin{tabular}{lll}
\multicolumn{1}{c}{ solution } & \multicolumn{1}{c}{ six acids } & seven acids \\
$\mathrm{TPh}\left(\mathrm{mg}_{\text {phenolic acids. }} \cdot \mathrm{L}^{-1}\right)$ & $461 \pm 9$ & $610 \pm 12$ \\
$\mathrm{COD}\left(\mathrm{mg}_{\mathrm{O}_{2}} \cdot \mathrm{L}^{-1}\right)$ & $1050 \pm 21$ & $1250 \pm 25$ \\
$\mathrm{BOD}_{5}\left(\mathrm{mg}_{\mathrm{O}_{2}} \cdot \mathrm{L}^{-1}\right)$ & $420 \pm 42$ & $544 \pm 54$ \\
$\mathrm{BOD}_{5} / \mathrm{COD}$ & 0.40 & 0.43 \\
\hline
\end{tabular}

2.3. Fenton Process. A $500 \mathrm{~mL}$ beaker was used to carry out the experiments containing $300 \mathrm{~mL}$ of the simulated olive mill wastewater. $\mathrm{pH}$ was checked with a Crison MicropH 2000 probe and corrected to $\mathrm{pH} 3.0$ with $\mathrm{NaOH}$ or $\mathrm{H}_{2} \mathrm{SO}_{4}$ (Panreac, $96 \%$ ), if necessary. The catalyst was introduced at the concentration of $1.0 \mathrm{~g} \cdot \mathrm{L}^{-1}$, and magnetic stirring was started. A $1 \mathrm{~h}$ time frame was given at these conditions without $\mathrm{pH}$ correction to evaluate the adsorption of the phenolic acids onto the catalyst. The $\mathrm{pH}$ increase due to the catalyst addition was measured and corrected only afterward, once the reaction was about to start. A first sample was withdrawn in order to evaluate if the catalyst had adsorbed any organic charge. With the $\mathrm{pH}$ at 3.0, hydrogen peroxide [Panreac, 33\%-stabilized QP ("quimicamente puro" (chemically pure))] was slowly poured at the concentration of $244 \mathrm{mM}$ (these values were optimized in a previous work $\left.{ }^{8}\right)$. At certain time intervals $(15,30,60,90$, and $120 \mathrm{~min}$ ), more samples were withdrawn by pipetting from the reactor to a filtration system (Buchner funnel, kitassato, and air pump) using a $0.45 \mu \mathrm{m}$ pore diameter quantitative filter paper to remove the solid catalyst from the liquid phase. $\mathrm{pH}$ was immediately raised to 10 to quench the remaining $\mathrm{H}_{2} \mathrm{O}_{2}$ and ${ }^{\circ} \mathrm{OH}$, stopping the reaction. Reaction parameters were adopted in order to be able to compare these work's results with previous studies from our research group $\left(\mathrm{pH},\left[\mathrm{H}_{2} \mathrm{O}_{2}\right]\right.$, and [catalyst]). In those former tests, the chemical regime was verified (mass transfer resistances are not significant) and the oxidation of both phenolic solutions is not obtained with the absence of either the catalyst or the hydrogen peroxide.

Each catalyst was evaluated through total phenolic content and chemical oxygen demand removals from the phenolic synthetic solution (techniques described on the next section). To avoid experimental errors, each test was replicated and the mean values are presented on the figures, along with the corresponding error bars. The average error encountered for total phenolic removal was $1.1 \%$, and for chemical oxygen demand removal this value was $0.7 \%$, representing very good agreement between experiments.

2.4. Analytical Techniques. A T60 U PG Instruments spectrophotometer was employed to detect the absorbance (wavelength $=765 \mathrm{~nm}$ ) after applying the Folin-Ciocalteu method $^{9}$ to infer the total phenolic content (TPh), as described in the standard procedure 5500B. ${ }^{10}$ To connect the obtained values of absorbance and the phenolic content, a calibration curve has been prepared using several concentrations of the synthetic solution to acquire an expression that uses the given absorbance after the Folin-Ciocalteu procedure to infer the phenolic content in milligrams of phenolic acids per liter $\left(\mathrm{mg}_{\text {phenolic acids }} \mathrm{L}^{-1}\right)$. Since the variations of the absorption values is high, two ranges of concentrations were adjusted into 
two equations: the low range, calculated from solutions containing $12-300 \mathrm{mg}_{\text {phenolic acids }} \cdot \mathrm{L}^{-1}$ (eq 1 , with a correlation factor, $R^{2}$, of 0.9981 ) and the high range, from 300 to 1000 $\mathrm{mg}_{\text {phenolic acids }} \cdot \mathrm{L}^{-1}$ (eq $\left.2, R^{2}=0.9997\right)$. Since the synthetic solution has a known concentration of approximately 450 $\mathrm{mg}_{\text {phenolic acids }} \cdot \mathrm{L}^{-1}$ for the case of six acids and $610 \mathrm{mg}_{\text {phenolic acids }}$. $\mathrm{L}^{-1}$ for the case of seven acids, these ranges fit all needs of this work.

$$
\begin{aligned}
& {[\mathrm{TPh}] /\left(\frac{\mathrm{mg}_{\text {phenolic acids }}}{L}\right)=\frac{(\text { absorbance }-0.0049)}{0.0005}} \\
& {[\mathrm{TPh}] /\left(\frac{\mathrm{mg}_{\text {phenolic acids }}}{L}\right)=\frac{(\text { absorbance }-0.0591)}{0.0003}}
\end{aligned}
$$

With the open reflux standard method $5220 \mathrm{~B}^{10}$ the chemical oxygen demand (COD) was determined using a WTW CR 3000 thermoreactor and a WTW MPM 3000 photometer. Standard method $5220 \mathrm{D}^{10}$ was used with inoculums obtained from garden soil to infer the biochemical oxygen demand in 5 days $\left(\mathrm{BOD}_{5}\right)$.

\section{RESULTS AND DISCUSSION}

3.1. Catalyst Characterization. $\mathrm{XRD}$ analysis shows that the catalysts are composed mainly by magnetite $\left(\mathrm{Fe}_{3} \mathrm{O}_{4}\right.$ or $\mathrm{FeO}$. $\mathrm{Fe}_{2} \mathrm{O}_{3}$, the most magnetic mineral found in nature ${ }^{11}$ ), and copper oxide, depending on the proportion of each samplewhich can be seen in Figure 1. The most salient difference on

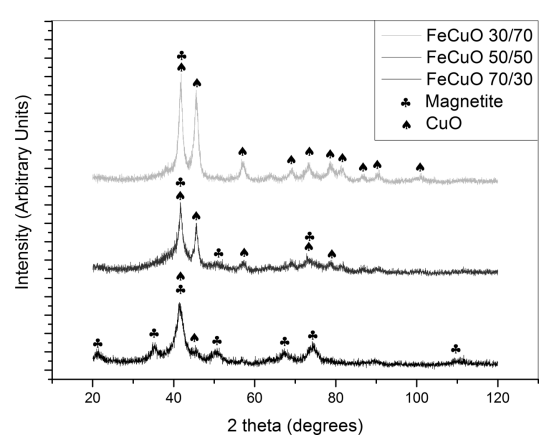

Figure 1. X-ray diffraction profiles for catalysts $\mathrm{Fe}-\mathrm{Cu}-\mathrm{O} 70 / 30$, $\mathrm{Fe}-$ $\mathrm{Cu}-\mathrm{O} 50 / 50$, and $\mathrm{Fe}-\mathrm{Cu}-\mathrm{O} 30 / 70$. Magnetite and copper oxide coincident peaks have been marked, as indicated on the legend.

the profiles regards the high peak presented at $\sim 45^{\circ}$ by the catalyst composed by higher copper proportion, $\mathrm{Fe}-\mathrm{Cu}-\mathrm{O}$ $30 / 70$. This peak is related to copper oxide. It becomes smaller at the $\mathrm{Fe}-\mathrm{Cu}-\mathrm{O} 50 / 50$ profile and almost absent in $\mathrm{FeCuO}$ $70 / 30$. At $\sim 42^{\circ}$, there is a coincident peak for both magnetite and copper oxide and that is why the three catalysts present it in a quite similar level with small reductions when the iron proportion increases. Regarding the several other smaller peaks, we can see much more magnetite in the $\mathrm{Fe}-\mathrm{Cu}-\mathrm{O} 70 / 30$ profile and copper oxides in $\mathrm{Fe}-\mathrm{Cu}-\mathrm{O} 30 / 70$.

Table 2 shows the data obtained from solids characterization. Both $\mathrm{Fe}-\mathrm{O}$ and $\mathrm{Cu}-\mathrm{O}$ were not analyzed since their results regarding organic charge removal as Fenton-like catalysts were poor.

Figure 2 shows the gas adsorption isotherms, and, as we can see, the three analyzed solids present type IV isotherms-

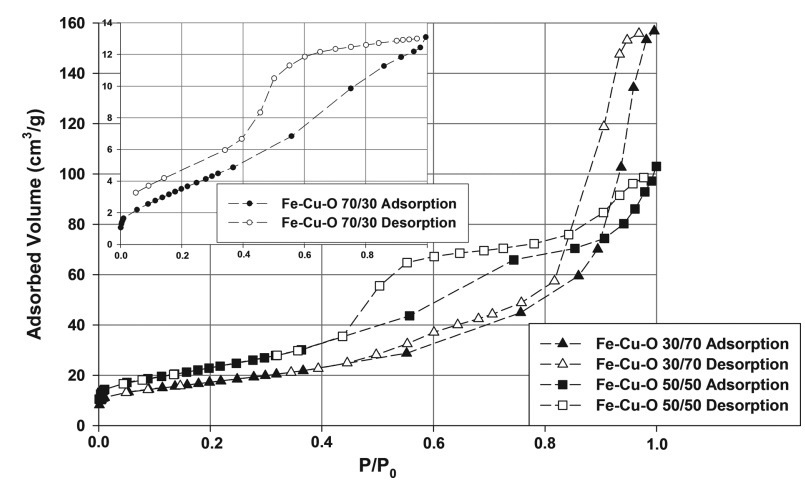

Figure 2. Gas adsorption isotherms (adsorbed volume versus relative pressure). Inlet: $\mathrm{Fe}-\mathrm{Cu}-\mathrm{O} 70 / 30$ curves, which have a lower scale.

which, according to Figueiredo and Ribeiro, ${ }^{12}$ are characterized by the hysteresis phenomenon and the presence of an elbow. Solids that present this type of isotherm usually have mesopores (pore size between 2 and $50 \mathrm{~nm}$ ). When the composition of the solids and their pore diameters are compared (Table 2), it seems that the augment on the copper content raises pore diameters: $\mathrm{Fe}-\mathrm{Cu}-\mathrm{O} 70 / 30$ presents pores with an average diameter of $5.7 \mathrm{~nm}$, while $\mathrm{Fe}-\mathrm{Cu}-\mathrm{O} 50 / 50$ presents a value of $7.5 \mathrm{~nm}$ and $\mathrm{Fe}-\mathrm{Cu}-\mathrm{O} 30 / 70,15.7 \mathrm{~nm}$.

As Figure 3 shows, for both $\mathrm{Fe}-\mathrm{Cu}-\mathrm{O} 70 / 30$ and $\mathrm{Fe}-\mathrm{Cu}-$ $\mathrm{O} 50 / 50$, higher pore volumes are found between pores with diameters of 3 and $4 \mathrm{~nm}$. $\mathrm{Fe}-\mathrm{Cu}-\mathrm{O} 30 / 70$, on the other hand, presents two pore volume peaks: one between 4 and $5 \mathrm{~nm}$ and another between 10 and $20 \mathrm{~nm}$. Helium porosimetry indicates that for higher contents of copper the porosity is increased: $\mathrm{Fe}-\mathrm{Cu}-\mathrm{O} 70 / 30$ has $39 \%$ porosity, while $\mathrm{Fe}-\mathrm{Cu}-\mathrm{O} 50 / 50$ has $45 \%$ and $\mathrm{Fe}-\mathrm{Cu}-\mathrm{O} 30 / 70,63 \%$. Regarding BET surface areas, $\mathrm{Fe}-\mathrm{Cu}-\mathrm{O} 50 / 50$ presents the larger value, $85 \mathrm{~m}^{2} \cdot \mathrm{g}^{-1}$, while $\mathrm{Fe}-\mathrm{Cu}-\mathrm{O} 30 / 70$ presents $62 \mathrm{~m}^{2} \cdot \mathrm{g}^{-1}$, and $\mathrm{Fe}-\mathrm{Cu}-\mathrm{O}$ $70 / 30$, only $14 \mathrm{~m}^{2} \cdot \mathrm{g}^{-1}$.

3.2. Organic Charge Depletion. By the adsorption tests, we detected none or insignificant amounts of both $\mathrm{TPh}$ and COD adsorbed by the catalysts in all cases. Figure 4 displays TPh removal profiles, where one can see that the oxidation curves for the simulated wastewater containing more initial compounds indicate a better process efficiency-enhanced results were found in all cases. $\mathrm{Fe}-\mathrm{Cu}-\mathrm{O} 50 / 50$ is pointed out as the most active solid, removing $100 \%$ of the phenolic content from solutions containing six and seven acids. This

Table 2. Catalysts Characterization: Solids Data

$\begin{array}{ll}\text { catalyst } & \mathrm{Fe}-\mathrm{Cu}-\mathrm{O} 70 / 30 \\ \text { BET surf area }\left(\mathrm{m}^{2} \cdot \mathrm{g}^{-1}\right) & 14 \\ \text { av pore diam }(\mathrm{nm}) & 5.7 \\ \text { single-point total pore } \mathrm{vol}\left(\mathrm{cm}^{3} \cdot \mathrm{g}^{-1}\right) & 0.0202 \\ \text { av density }\left(\mathrm{g} \cdot \mathrm{cm}^{-3}\right) & 4.27 \\ \text { porosity }(\%) & 39\end{array}$

$\begin{array}{ll}\mathrm{Fe}-\mathrm{Cu}-\mathrm{O} 50 / 50 & \mathrm{Fe}-\mathrm{Cu}-\mathrm{O} 30 / 70 \\ 85 & 62 \\ 7.5 & 15.7 \\ 0.1594 & 0.2426 \\ 4.45 & 4.79 \\ 45 & 63\end{array}$



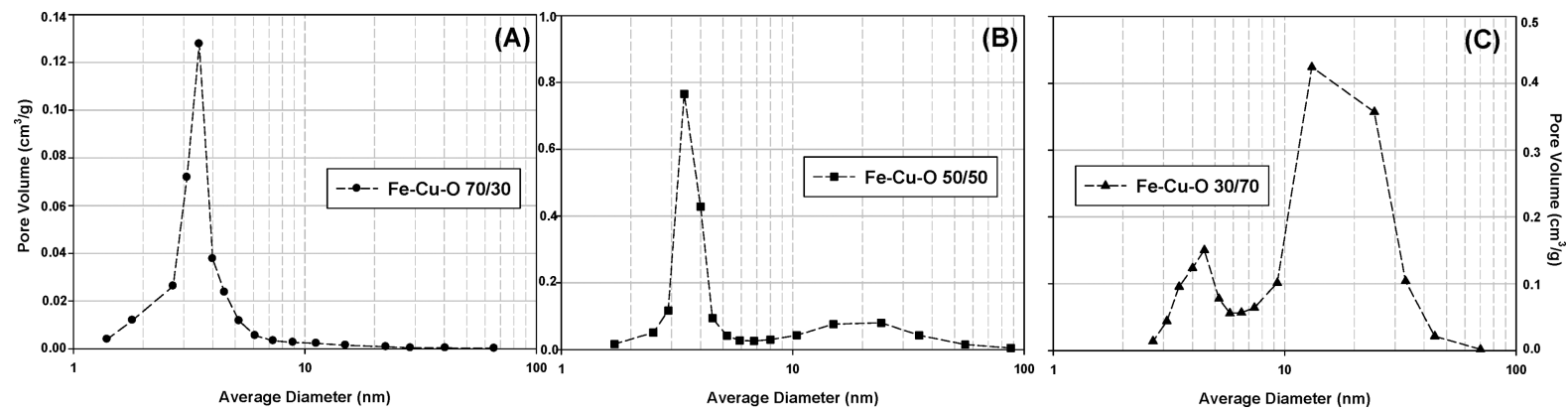

Figure 3. Pore size versus pore volume for the following catalysts: (A) $\mathrm{Fe}-\mathrm{Cu}-\mathrm{O} 70 / 30$, (B) $\mathrm{Fe}-\mathrm{Cu}-\mathrm{O} 50 / 50$, and (C) $\mathrm{Fe}-\mathrm{Cu}-\mathrm{O} 30 / 70$.

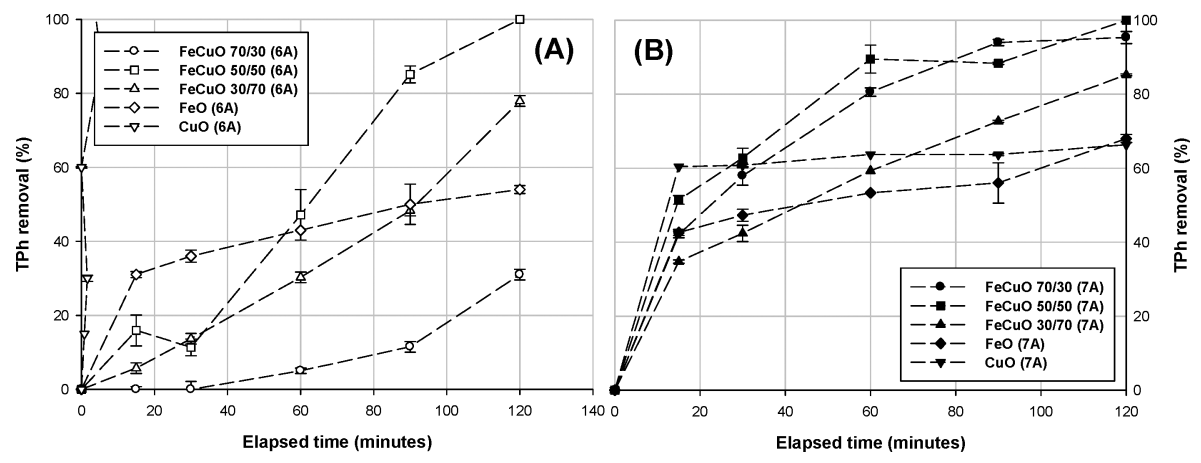

Figure 4. Total phenolic content removal profiles: (A) six acids mother solution; (B) seven acids mother solution.
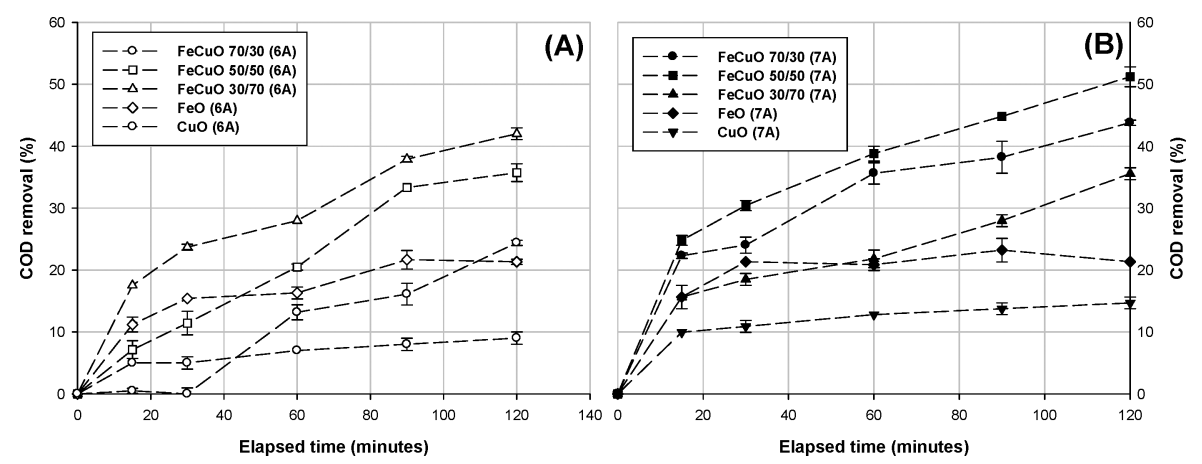

Figure 5. Chemical oxygen demand removal profiles: open symbols, six acids mother solution; closed symbols, seven acids mother solution.

solid was followed by $\mathrm{Fe}-\mathrm{Cu}-\mathrm{O}$ 30/70, which could oxidize $85 \%$ of the phenolic content from the solution containing seven acids solutions and $78 \%$ from the solution containing six acids. $\mathrm{Fe}-\mathrm{O}$ and $\mathrm{Cu}-\mathrm{O}$ presented similar efficiencies in both cases: 68 and $66 \%$ removals, respectively, from the seven acids solution, and 54 and $55 \%$ phenolic content abatement from the solution containing six acids. The $\mathrm{Fe}-\mathrm{Cu}-\mathrm{O} 70 / 30$ catalyst presented the most discrepant values when the TPh reductions from both solutions are compared: $95 \%$ of the phenolic acids were removed from the solution containing seven phenolic acids when only $31 \%$ were removed from the other solutionindicating a strong participation of the free radicals in solution, especially in this last case.

COD removal profiles are displayed in Figure 5. Regarding this parameter, catalysts efficiency order is the same for both COD and TPh abatements in the case of the seven acids solution. Being the most efficient, $\mathrm{Fe}-\mathrm{Cu}-\mathrm{O} 50 / 50$ again topped this list, with 51\% COD removal. Regarding the six acids mixture, however, the best solid is the $\mathrm{Fe}-\mathrm{Cu}-\mathrm{O} 30 / 70$ (42\% COD abatement). For the seven acids solution treatment, the remaining solids are as follows: $\mathrm{Fe}-\mathrm{Cu}-\mathrm{O} 70 / 30(44 \%$
COD depletion), $\mathrm{Fe}-\mathrm{Cu}-\mathrm{O} 30 / 70$ (36\%), $\mathrm{Fe}-\mathrm{O}$ (21\%), and $\mathrm{Cu}-\mathrm{O}(9 \%)$. Additionally, the order for the six acids solution oxidation, after the $\mathrm{Fe}-\mathrm{Cu}-\mathrm{O} 30 / 70$ comes $\mathrm{Fe}-\mathrm{Cu}-\mathrm{O} 50 / 50$ (36\%), $\mathrm{Fe}-\mathrm{Cu}-\mathrm{O} 70 / 30$ (24\%), $\mathrm{Fe}-\mathrm{O}(21 \%)$, and $\mathrm{Cu}-\mathrm{O}$ (15\%). Being so, the optimal ratio between copper and iron to produce Fenton catalysts, regarding $\mathrm{TPh}$ and $\mathrm{COD}$ removals, is $50 / 50$ - unless for COD reduction of the six acids mother solution, when the removal is $6 \%$ higher for the $30 / 70$ ratio.

Through the analysis of Figures 4 and 5, one can also notice that the percentage removals of COD and $\mathrm{TPh}$ are significantly higher when more acids comprise the mother solution. The treatment enhancement might occur because the radicals present in the reaction mixture can collaborate to the augment on the oxidizing potential in a synergistic manner.

As mentioned by Zhu et al., ${ }^{13}$ the gallic acid can act as a reducing agent, which could reduce $\mathrm{Fe}$ (III) to $\mathrm{Fe}$ (II) and/or $\mathrm{Cu}(\mathrm{II})$ to $\mathrm{Cu}(\mathrm{I})$. Since this compound was only present on the seven acids mother solution, the metal's valence alteration could increase the Fenton efficiency, since the reduced forms of the metals are able to generate hydroxyl radicals faster and, therefore, increase the oxidation of the other compounds in 
Table 3. $\mathrm{BOD}_{5} / \mathrm{COD}$ Results for All Catalysts

$\begin{array}{llll}\text { catalyst } & \mathrm{Fe}-\mathrm{Cu}-\mathrm{O} 70 / 30 & \mathrm{Fe}-\mathrm{Cu}-\mathrm{O} 50 / 50 & \mathrm{Fe}-\mathrm{Cu}-\mathrm{O} 30 / 70 \\ \mathrm{BOD}_{5} / \mathrm{COD} \text { (six acids) } & 0.20 & 0.17 & 0.23 \\ \mathrm{BOD}_{5} / \mathrm{COD} \text { (seven acids) } & 0.24 & 0.18 & 0.14\end{array}$

solution. Yet, it is mandatory to mention that the concentrations of gallic acid by Zhu were much higher and could only increase the efficiency of the used system in about $8 \%$ and that he only analyzed the removal of a single compound and not the full degradation of the broken molecules, such as in the present work. Therefore, this fact could only explain a small part of the system's oxidative power differences presented here-being, still, the cooxidation responsible for the majority of the changes.

3.3. Biodegradability Assessment. Since the phenolic composition of olive mill wastewaters presents low biodegradability to bacteria, biological plants are not recommended to treat these effluents directly. As the mother solutions also have this characteristic, something desirable from the Fenton treatment is to enhance those two parameters. Yet, although $\mathrm{Fe}-\mathrm{Cu}-\mathrm{O}$ catalysts reached good $\mathrm{COD}$ removals, the $\mathrm{BOD}_{5} /$ COD ratio was reduced from 0.45 to less than 0.25 , indicating that the biodegradability was somehow affected (what can be seen in Table 3). The presence of leached copper cannot be pointed to as the cause of this because the catalyst without this metal, $\mathrm{Fe}-\mathrm{O}$, also presented a similar $\mathrm{BOD}_{5}$ result. Intermediate compounds might be refracting the biological consumption of the organic charge. Since the composition of all catalysts is qualitatively the same (copper and iron oxides), the oxidation pathways might have been similar and this would explain the biodegradability loss for all cases.

\section{CONCLUSION}

The interaction between copper and iron oxides in the catalysts showed good results, since in all cases the catalysts comprising both metals showed faster and higher organic charge degradation than $\mathrm{Fe}-\mathrm{O}$ and/or $\mathrm{Cu}-\mathrm{O}$. Comparing the two mother solutions oxidation, it can be said that the mixture containing more acids is easier to degrade (this was observed in almost all cases) - meaning that the cooxidation phenomenon is occurring and enhancing the process efficiency. The iron/ copper molar ratio of 50/50 can be pointed out as the one that will create more active $\mathrm{Fe}-\mathrm{Cu}-\mathrm{O}$ catalysts, since the $\mathrm{TPh}$ and COD abatements for this solid were the best in all cases except one (where the removal difference is only 6\%). Despite the interesting data about organic charge depletion, these catalysts were not tested in what regards the leaching behavior since the biodegradability was reduced in every experiment-especially for the most active solid $(\mathrm{Fe}-\mathrm{Cu}-\mathrm{O}$ 50/50) that most promoted organic matter oxidation.

\section{AUTHOR INFORMATION}

\section{Corresponding Author}

*Tel.: +351-239798723. Fax: +351-239798703. E-mail: rosaqf@eq.uc.pt.

\section{Notes}

The authors declare no competing financial interest.

\section{ACKNOWLEDGMENTS}

A.F.R. and R.C.M. gratefully acknowledge FCT-Fundação para a Ciência e Tecnologia, Portugal, for financial support under Grants SFRH/BD/63653/2009 and SFRH/BPD/
$72200 / 2010$ and also for Contract PTDC/EQU-ERQ/ $113308 / 2009$.

\section{REFERENCES}

(1) Fenton, H. J. H. Oxidation of tartaric acid in presence of iron. J. Chem. Soc. 1894, 65, 899-910.

(2) Neyens, E.; Baeyens, J. A review of classic Fenton's peroxidation as an advanced oxidation technique. J. Hazard. Mater. 2003, B98, 3350.

(3) Haber, F.; Weiss, J. On the catalysis of hydroperoxide. Naturwissenschaften 1932, 51, 948-950.

(4) Imamura, S.; Doi, A.; Ishida, S. Wet oxidation of ammonia catalyzed by cerium-based composite oxides. Ind. Eng. Chem. Prod. Res. Dev. 1985, 24, 75-80.

(5) Martins, R. C.; Rossi, A. F.; Quinta-Ferreira, R. M. Fenton's oxidation process for phenolic wastewater remediation and biodegradability enhancement. J. Hazard. Mater. 2010, 180, 716-721.

(6) Rossi, A. F.; Amaral-Silva, N.; Martins, R. C.; Quinta-Ferreira, R. $M$. Heterogeneous Fenton using ceria based catalysts: effects of the calcination temperature in the process efficiency. Appl. Catal., B 2012, 111-112, 254-263.

(7) Lopes, R. J. G.; Silva, A. M. T.; Quinta-Ferreira, R. M. Screening of catalysts and effect of temperature for kinetic degradation studies of aromatic compounds during wet oxidation. Appl. Catal., B 2007, 73, 193-202.

(8) Martins, R. C.; Amaral-Silva, N.; Quinta-Ferreira, R. M. Ceria based solid catalysts for Fenton's depuration of phenolic wastewaters: Biodegradability enhancement and toxicity removal. Appl. Catal., B 2010, 99, 135-144.

(9) Folin, O.; Ciocalteu, V. On tyrosine and tryptophan determination in protein. J. Biol. Chem. 1927, 73, 627.

(10) Greenberg, A. E.; Clesceri, L. S.; Eaton, A. D. Standard methods for the examination of water and wastewater; American Public Health Association: Washington, DC, USA, 1985.

(11) Harrison, R. J.; Dunin-Borkowski, R. E.; Putnis, A. Direct imaging of nanoscale magnetic interactions in minerals. Proc. Natl. Acad. Sci. U. S. A. 2002, 99, 16556-16561.

(12) Figueiredo, J. L.; Ribeiro, F. R. Catálise Heterogénea; Fundação Calouste Gulbenkian: Lisboa, Portugal, 1989.

(13) Fukuchi, S.; Nishimoto, R.; Fukushima, M.; Zhu, Q. Effects of reducing agents on the degradation of 2,4,6-tribromophenol in a heterogeneous Fenton-like system with an iron-loaded natural zeolite. Appl. Catal., B 2014, 147, 411-419. 